\title{
Work-related stress and psychosomatic medicine
}

\author{
Mutsuhiro Nakao ${ }^{1,2}$
}

\begin{abstract}
This article introduces key concepts of work-related stress relevant to the clinical and research fields of psychosomatic medicine. Stress is a term used to describe the body's physiological and/or psychological reaction to circumstances that require behavioral adjustment. According to the Japanese National Survey of Health, the most frequent stressors are work-related problems, followed by health-related and then financial problems. Conceptually, work-related stress includes a variety of conditions, such as overwork, unemployment or job insecurity, and lack of work-family balance. Job stress has been linked to a range of adverse physical and mental health outcomes, such as cardiovascular disease, insomnia, depression, and anxiety. Stressful working conditions can also impact employee well-being indirectly by directly contributing to negative health behaviors or by limiting an individual's ability to make positive changes to lifestyle behaviors, such as smoking and sedentary behavior. Over the past two decades, two major job stress models have dominated the occupational health literature: the job demand-control-support model and the effort-reward imbalance model. In both models, standardized questionnaires have been developed and frequently used to assess job stress. Unemployment has also been reported to be associated with increased mortality and morbidity, such as by cardiovascular disease, stroke, and suicide. During the past two decades, a trend toward more flexible labor markets has emerged in the private and public sectors of developed countries, and temporary employment arrangements have increased. Temporary workers often complain that they are more productive but receive less compensation than permanent workers. A significant body of research reveals that temporary workers have reported chronic work-related stress for years. The Japanese government has urged all employers to implement four approaches to comprehensive mind/body health care for stress management in the workplace: focusing on individuals, utilizing supervisory lines, enlisting company health care staff, and referring to medical resources outside the company. Good communications between occupational health practitioners and physicians in charge in hospitals/clinics help employees with psychosomatic distress to return to work, and it is critical for psychosomatic practitioners and researchers to understand the basic ideas of work-related stress from the viewpoint of occupational health.
\end{abstract}

\section{Introduction}

Stress is a term used to define the body's physiological and/or psychological reaction to circumstances that require behavioral adjustment. According to the Japanese National Survey of Health in 2004 [1], 49\% of individuals aged 12 years or older reported experiencing stress in their daily lives. This survey examined stress in 28 domains, including work, family, and neighborhood relationships, as well as living-, social-, financial-, and health-related situations. Work-related problems were the most frequent stressors, followed by health-related and then financial problems.

Correspondence: mnakao@med.teikyo-u.ac.jp

${ }^{1}$ Department of Hygiene and Public Health, Teikyo University School of Medicine, Tokyo, Japan
The Japanese Society of Psychosomatic Medicine defines "psychosomatic illness" as any physical condition with organic or functional damage affected by psychosocial factors in the process of its onset or development [2]. This definition largely corresponds to that given in the most recent version of the Diagnostic and Statistical Manual of Mental Disorders, Fourth Edition, Text Revision (DSM-IV-TR), published by the American Psychiatric Association [3]: "psychosocial factors affecting general medical conditions (code 316.00)." In the previous edition of the DSM (DSM-III) and its revision (DSM-III-R) [4], the psychosocial stressor content was defined according to severity, as shown in Table 1 . In our previous study, which used axis IV of the DSM-III$\mathrm{R}$ in a psychosomatic outpatient clinic $(\mathrm{n}=868)$ [5], the majority of patients had mild psychosocial stressors 
Table 1 Severity of psychosocial stressors in adults: DSMIII-R axis IV [4]

\begin{tabular}{|c|c|c|}
\hline \multirow[b]{2}{*}{ Severity } & \multicolumn{2}{|c|}{ Examples of psychosocial stressors in adulthood } \\
\hline & Acute events & Enduring circumstances \\
\hline None & None & None \\
\hline \multirow[t]{3}{*}{ Mild } & $\begin{array}{l}\text { Broke up with boyfriend/ } \\
\text { girlfriend }\end{array}$ & Family arguments \\
\hline & $\begin{array}{l}\text { Started or graduated from } \\
\text { school }\end{array}$ & $\underline{\text { Job dissatisfaction }}$ \\
\hline & Child left home & $\begin{array}{l}\text { Residence in high-crime } \\
\text { region }\end{array}$ \\
\hline \multirow[t]{4}{*}{ Moderate } & Marriage & Marital discord \\
\hline & Marital separation & Serious financial problems \\
\hline & Loss of job & Trouble with boss \\
\hline & $\overline{\text { Miscarriage }}$ & Being a single parent \\
\hline \multirow[t]{2}{*}{ Severe } & Divorce & Unemployment \\
\hline & Birth of first child & Poverty \\
\hline \multirow[t]{3}{*}{ Extreme } & Death of spouse & Serious chronic illness \\
\hline & $\begin{array}{l}\text { Serious physical illness } \\
\text { diagnosed }\end{array}$ & $\begin{array}{l}\text { Ongoing physical or sexual } \\
\text { abuse }\end{array}$ \\
\hline & Victim of rape & \\
\hline \multirow[t]{3}{*}{ Catastrophic } & Death of child & Captivity as hostage \\
\hline & Suicide of spouse & $\begin{array}{l}\text { Concentration camp } \\
\text { experience }\end{array}$ \\
\hline & Devastating natural disaster & \\
\hline
\end{tabular}

(58\%), followed by moderate (21\%), none (10\%), and severe stressors (5\%). In the DSM-IV, axis IV has changed from rating the severity of psychosocial stressors to a simple categorization of psychosocial stressors, as shown in Table 2. Evaluating patients according to this new axis IV $(\mathrm{n}=564)$ showed that the most frequent psychosocial stressors were occupational problems

Table 2 Categories of psychosocial and environmental problems: DSM-IV-TR axis IV [3]

\begin{tabular}{l} 
Category \\
\hline Problems with primary support group \\
Problems related to the social environment \\
Educational problems \\
Occupational problems (examples below) \\
$\quad$ Unemployment \\
Threat of job loss \\
Stressful work schedule \\
$\quad$ Difficult working conditions \\
$\quad$ Job dissatisfaction \\
$\quad$ Job change \\
Discord with boss or co-workers \\
Housing problems \\
Economic problems \\
Problems with access to health care services \\
Problems related to interaction with the legal system/crime \\
Other psychosocial and environmental problems \\
\hline
\end{tabular}

(23\%), followed by issues related to the primary support group (21\%), social environment (5\%), and education (5\%) [5].

Although psychosomatic patients frequently identify work-related problems, these stressors have typically been considered to be relatively mild in severity. For example, acute events, such as job loss or retirement, were regarded as moderate psychosocial stressors in the DSM-III-R assessment, whereas familial events, such as divorce or birth of a first child, were regarded as severe stressors. One of the reasons for such rating criteria is that, while work-related stress is common, it is difficult to assess diagnostically. However, the working environment in Japan and other countries has been changing dramatically. Many employees have been forced to work harder because of ongoing business restructuring and some have suffered from psychosomatic symptoms caused by their work, while others have committed suicide and have been officially acknowledged as victims of depression caused by overwork. Thus, psychosomatic clinicians should pay particular attention to work-related stress when evaluating patients.

Work-related stress includes the concepts of job stress, employment status, job insecurity, and lack of workfamily balance. This article introduces key work-related stress concepts (i.e., the job stress model and effects of unstable job conditions on health) relevant to the clinical and research fields of psychosomatic medicine.

\section{Concept of job stress}

Job stress is a substantial and growing concern for workers, their advocates, employers, occupational health and safety regulators, and workers' compensation programs [6,7]. The US National Institute for Occupational Safety and Health defines job stress as "the harmful physical and emotional responses that occur when the requirements of a job do not match the capabilities, resources, or needs of the worker" [8]. Job stress has been linked to a range of adverse physical and mental health outcomes, including cardiovascular disease $[9,10]$, insomnia [11], depression, and anxiety [12]. Stressful working conditions can also impact employee well-being by directly contributing to negative health behaviors or by indirectly limiting an individual's ability to make positive changes to lifestyle behaviors, such as smoking and sedentary behavior [13].

Job stress can result from the job itself (e.g., heavy workload, low input into decision making) or the social and organizational contexts in which the job is performed (e.g., poor communication, interpersonal conflict). There is considerable variation in the way workers perceive and respond to the environments in which they work. Personal (e.g., coping skills) and situational variables (e.g., support from supervisors) influence 
the onset and duration of job stress, and circumstances that one person finds demanding and stressful may be perceived by others as challenging and simulating [14].

Figure 1 shows the process underlying development of job stress as well as a systemic approach to reducing job stress $[6,15,16]$. Workplace stressors can be addressed through occupational health and safety: stress can arise through a combination of work- and non-work-related circumstances and can be addressed by integrating occupational health and safety, health promotion, and other approaches, including psychosomatic medicine. Short-term and temporary responses can be physiological (e.g., elevated blood pressure), psychological (e.g., depression), or behavioral (e.g., excessive alcohol drinking). Over the long-term, such responses can lead to disease conditions of a physical (e.g., hypertension), psychological (e.g., depressive disorder), or behavioral nature (e.g., alcoholism).

\section{Job stress model}

Over the past two decades, two major job stress models have dominated the occupational health literature: the job demand-control-support model proposed by Karasek and Theorell [17] and the effort-reward imbalance (ERI) model developed by Siegrist [18].

Karasek described two dimensions of job demand and control. Job control or decision latitude comprises decision authority (controllability over work) and skill discretion (variety of work and opportunity for use of skills). The ratio of job demand to job control is often called job strain, and Figure 2 shows four categories of jobs, divided according to job strain (i.e., high-strain, active, low-strain, and passive) $[19,20]$. The high-strain group is at the highest risk: psychosomatic symptoms are predicted to be severe when the psychological demands of a job are high and the workers' decision latitude is low because the worker lacks the resources to deal with demands. The active group may experience intensely demanding jobs, but the workers have sufficient control over their activities and the freedom to use available skills. Thus, average psychological strain and active leisure time are predicted. The low-strain group, experiencing few psychological demands and high levels of control, should have below-average levels of psychological strain and lower risk of ill health because these individuals have relatively few challenges, and decision latitude allows them to respond optimally to these challenges. The passive group, characterized by low demands and low control, is predicted to be demotivated, which may induce atrophy of skills and abilities, but only average levels of psychological strain and health risk are expected [21].

Further work by Johnson and Thorell $[17,22]$ added the important dimension of occupational social support to Karasek's model, as it had been noted that support from supervisors and co-workers buffered the effects of high demands and low control. This integrated model is called the demand-control-support model. In this

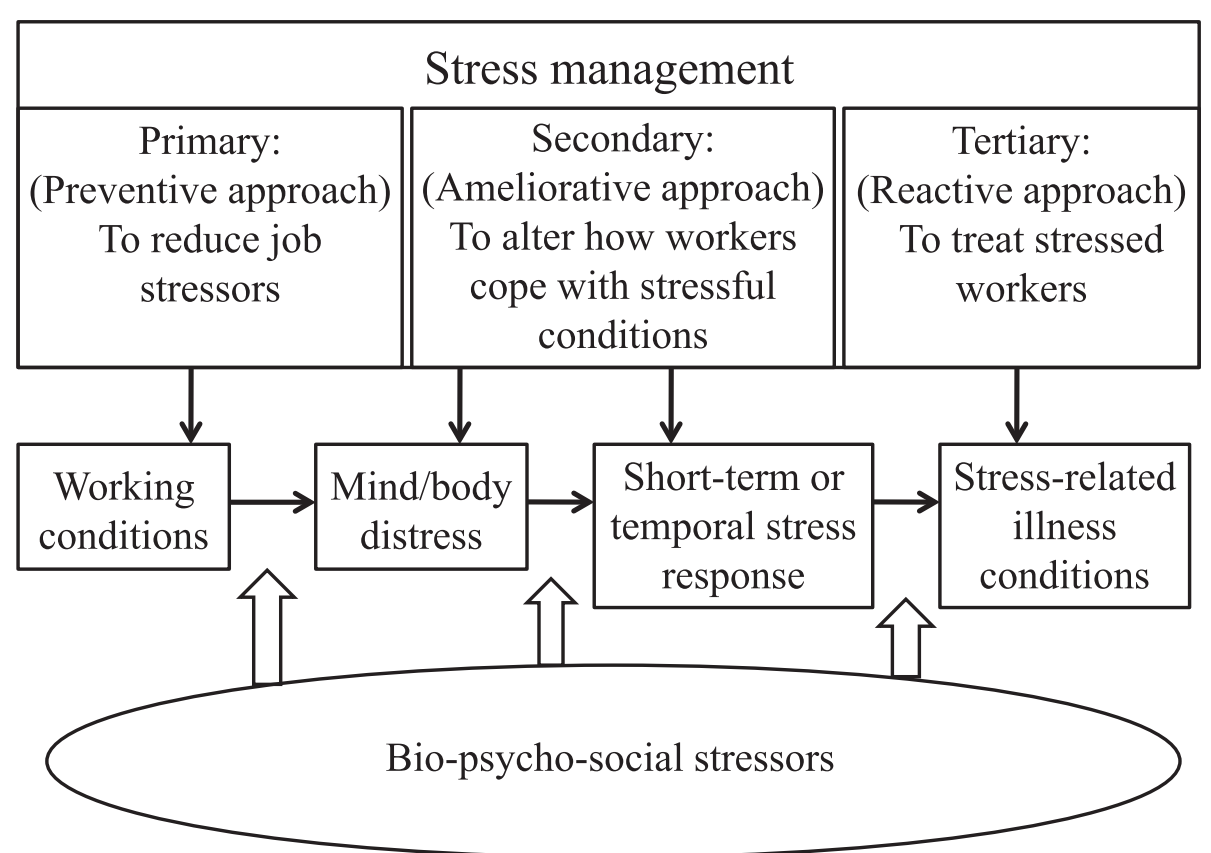

Figure 1 Job stress process and systemic approach to stress management. This figure was adapted from models that were previously proposed $[6,15,16]$. 


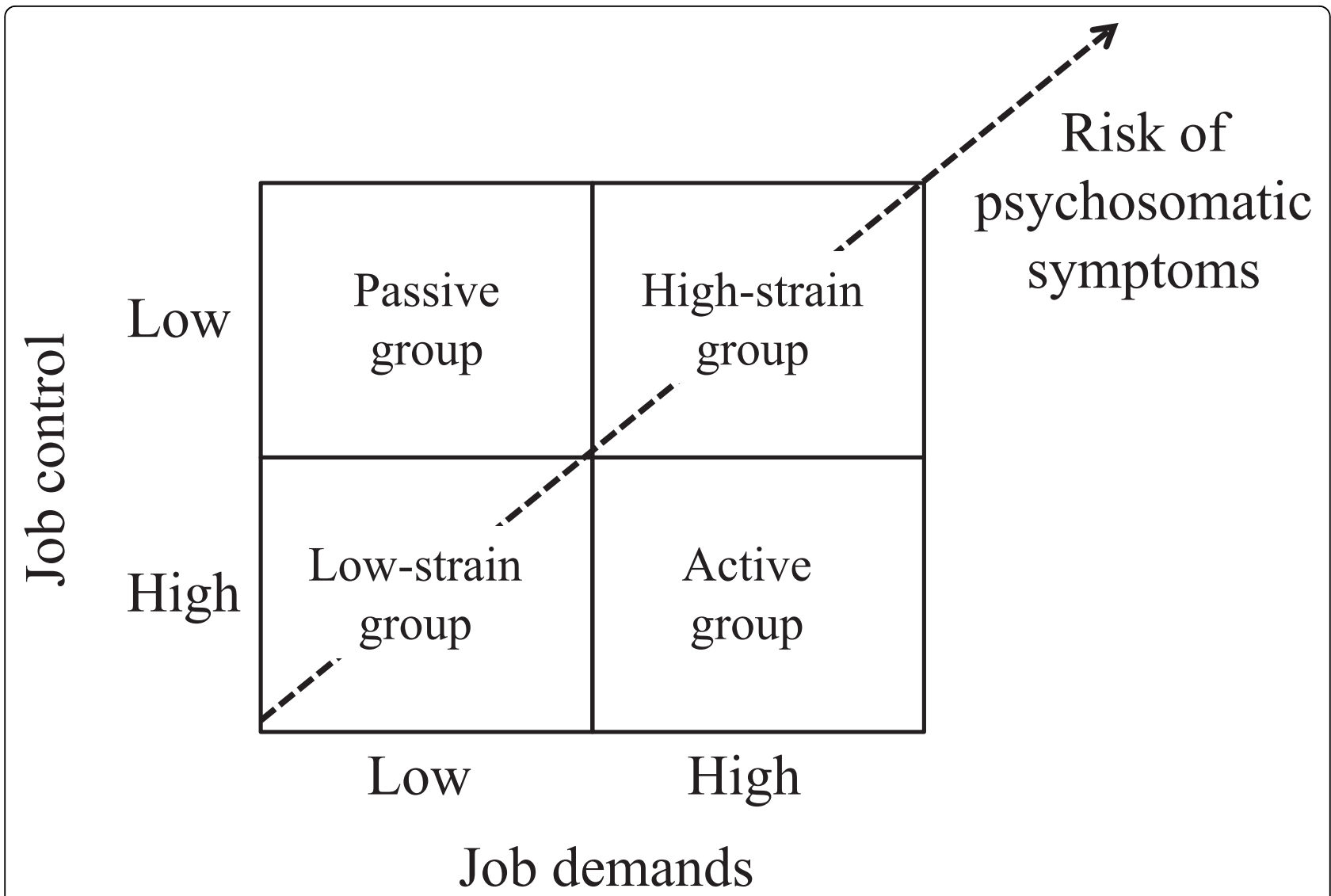

Figure 2 Job strain groups according to job demands and control. This figure was adapted from the models that were previously proposed $[19,20]$.

context, determining whether a social network provides support to mediate psychosocial strain is decisive in the development of illness [23]. Working conditions that include both high strain and low social support (i.e., isostrain) have the greatest negative impact.

In Siegrist's ERI model, high-cost and low-gain work conditions are particularly stressful. Work offers opportunities to gain self-esteem, efficacy, and integration. According to the social exchange theory, workers invest effort and expect these rewards in return. If there is an imbalance in the expected exchange that prevents workers from receiving rewards, then psychological distress occurs, accompanied by physiological arousal. Thus, one risk factor for ill health is a combination of high effort at work, which may entail intrinsic effort and innate competitiveness and hostility, combined with high extrinsic job demands and little reward in terms of salary, promotion, or esteem.

\section{Example of job stress study}

A standardized questionnaire, such as the Job Content Questionnaire (JCQ), is frequently used as an assessment tool for the job demand-control-support model [24]. The reliability and validity of the Japanese version of the JCQ have been demonstrated [25]. Using this version of the JCQ, we conducted a cross-sectional study of workrelated stress and arterial stiffness in 396 male workers, aged 24 to 39 years, who were employed in a Japanese information-service company [26]. Brachial-pulse wave velocity (baPWV) was used to assess the degree of arteriosclerosis, and the Profile of Mood State (POMS) was used to assess mood. Results indicated that the two POMS scales, tension-anxiety and anger-hostility, were significantly higher in the high-demand and high-strain groups compared with the low-demand and low-strain groups (Table 3), suggesting that work-related stress affects mood. However, job strain was negatively associated with baPWV, even after controlling for significant cardiovascular disease (CVD) risk factors, such as age, heart rate, and serum noradrenaline levels, as shown in Table 3. These effects were in direct opposition with what was predicted based on the job strain hypothesis, which suggests that workers with high job strain have an increased risk for CVD [27]. However, the results of the Coronary Artery Risk Disease in Young Adults study [28] were compatible with our study, showing inverse 
Table 3 Effects of job stress, cardiovascular disease risk factors, and mood state on brachial-ankle pulse velocity in 396 male workers

\begin{tabular}{|c|c|c|}
\hline \multirow[b]{2}{*}{ Independent variables } & \multicolumn{2}{|c|}{ Regresion analysis } \\
\hline & Univariate & Multivariate $^{a}$ \\
\hline \multicolumn{3}{|l|}{ Job Content Questionnaire ${ }^{b}$} \\
\hline Job demands & $N S^{c}$ & $(-)^{*}$ \\
\hline Job control & $(+)^{* *}$ & $(+)^{* *}$ \\
\hline Social support & NS & - \\
\hline \multicolumn{3}{|l|}{ CVD risk factors } \\
\hline Age & $(+)^{* * *}$ & $(+)^{* * *}$ \\
\hline Heart & $(+)^{* * *}$ & $(+)^{* * *}$ \\
\hline Body mass index & $(+)^{* *}$ & NS \\
\hline \multicolumn{3}{|l|}{ Serum lipid levels } \\
\hline Total cholestrerol & $(+)^{* * *}$ & NS \\
\hline Triglyceride & $(+)^{* * *}$ & - \\
\hline Fasting glucose levels & $(+)^{*}$ & NS \\
\hline \multicolumn{3}{|l|}{ Serum catecholamine levels } \\
\hline Adrenaline & NS & - \\
\hline Noradrenaline & $(+)^{* *}$ & $(+)^{*}$ \\
\hline Dopamine & NS & - \\
\hline Cigarettes smoked per day & NS & - \\
\hline \multicolumn{3}{|l|}{ Profile of Mood State } \\
\hline Tension-Anxiety & NS & - \\
\hline Anger-Hostility & NS & - \\
\hline
\end{tabular}

a Variables with $p<0.05$ in the univariate analysis were selected as independent variables in the multivariate analysis. Serum triglyceride levels were excluded in the multivariate analysis because of the collinearity between total cholesterol and triglyceride.

b The reasons for the inverse relationship between higher brachial-ankle pulse velocity and higher job strain (i.e., higher job demands and lower job control) are discussed in the text.

${ }^{c} \mathrm{NS}$, not significant $(p>0.05)$.

${ }^{*} p<0.05,{ }^{* *} p<0.01,{ }^{* * *} p<0.001$

This table was completed by reanalyzing data from our previous study [26].

associations with risk factors for high job demands, low control, and job strain in young adults. In our study [26], subjects in the low-job-strain group tended to have higher diastolic blood pressure, body mass index, serum levels of total cholesterol, blood sugar levels, and ethanol consumption compared with the high-job-strain group. Thus, it is possible that subjects in the low-job-strain group coped with the distress of overwork by adopting unhealthy lifestyles. Another possible explanation is that age-related cultural factors might affect the relationship between the JCQ and baPWV. The inconsistency of the current results with other studies raises concerns about applying the JCQ to Japanese workers and suggests that other factors, such as cultural influence and age, should also be considered.

A standardized ERI questionnaire has been developed and includes three main scales: extrinsic effort, reward, and over-commitment [29]. A score for the effort-reward ratio was obtained by calculating the log-transformed ratio of extrinsic effort to reward as a continuous measure. Over-commitment indicates a state of exhaustive coping that reflects continued, frustrated efforts and negative feelings associated with this state. A Japanese version of the ERI questionnaire was developed by Tsutsumi and colleagues [30]. To confirm the applicability of the ERI model of over-commitment to the assessment of fatigue, we investigated 95 male workers in a Japanese information-technology company using the Japanese versions of the ERI questionnaire and the POMS [31]. All had worked overtime, according to the standards of the Ministry of Health, Labor and Welfare in Japan: they worked at least 100 hours during the preceding 1-month period and/or at least 80 hours per month over the preceding 2- to 6-month period. Results showed that the effort-reward ratio was significantly positively correlated with the POMS fatigue scores, and there was a 3-way interaction among over-commitment scores, POMS fatigue scores, and effort-reward ratio. Specifically, the increase in psychological fatigue that accompanied increased ERI scores was greater in workers with higher over-commitment than in those with lower over-commitment, as shown in Figure 3. These results suggest a need for interventions to reduce worker ERI, over-commitment, and fatigue, to improve productivity, and to limit occupational accidents.

\section{Unemployment and job insecurity}

Evidence has consistently indicated that unemployment is associated with increased mortality and morbidity

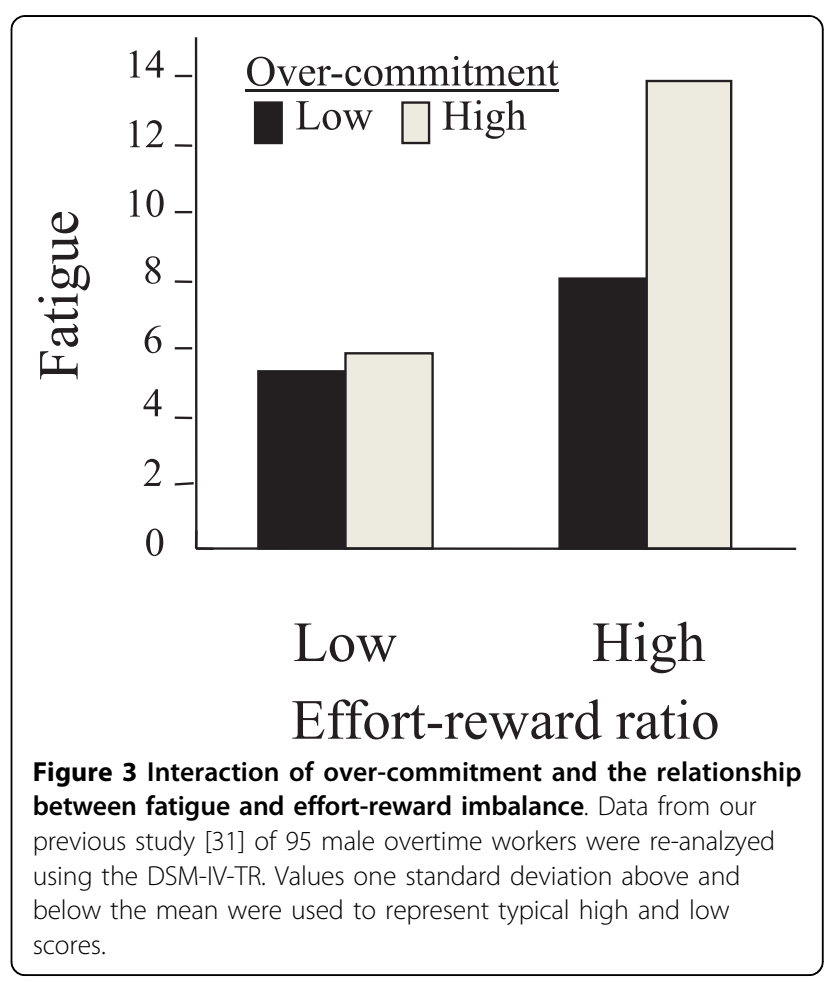


[32-34]. Due to the labor market structure, previous studies defined work status as a dichotomy (i.e., employed or unemployed). However, during the past two decades, a trend toward more flexible labor markets has emerged in the private and public sectors of developed countries. Employers and policy makers have seen labor-market flexibility as a means of improving worker performance and adaptability in the face of technical change and increasing globalization. As a result, the labor market has increasingly moved toward a core-periphery structure in which the core comprises employees with relatively secure permanent jobs, and the periphery consists of the "buffer work force" with various temporary, unstable, and insecure work arrangements, among which the outermost sector has the highest risk for unemployment [35-37].

The firing of temporary workers is an issue of great concern in Japan. The world financial crisis became publicly known around October 2008 with the fall of Lehman Brothers. The Japanese economy depends greatly on the American economy; it is often said, "When America catches a cold, Japan risks pneumonia." In Japan, temporary workers started losing their jobs as a result of the economic recession. Because a temporary employment system has only recently been initiated in Japan, this rapid increase in firings will have a major impact on workers, those seeking jobs, and their family members [38]. The largest issue is that the Japanese health management system, including accident insurance and medical benefits, does not accommodate the variety of current employment patterns. Of great concern, little medical research has focused on possible risks of mental health problems among temporary workers, who face high levels of job insecurity.

Temporary workers often complain that they are more productive but receive lower compensation than permanent workers [39]. Our own research has found that term-limited workers tend to work more hours and experience symptoms of fatigue more frequently than do permanent workers [40]. A significant body of research [41] reveals that temporary workers have reported chronic work-related stress for years, but the recent sudden increase in job insecurity is beyond expectation; it is akin to an acute trauma or suddenonset disaster that gives temporary workers a "one-two punch" of both acute and chronic stress.

Practitioners of psychosomatic medicine have been seeing many patients who are temporary workers complaining of psychosomatic distress due to job insecurity; indeed, some have already attempted suicide. This situation is not limited to the Japanese population; it is a problem in all industrial countries. The growing frequency with which temporary workers are being fired threatens to create a situation that may be termed "creeping" mental health problems. Thus, in this author's opinion, we have a responsibility to speak about such issues publicly to determine whether temporary working conditions really affect health status.

\section{Management of job stress}

The Japanese government has urged all employers to implement four approaches to comprehensive mind/ body health care: focusing on individuals, utilizing supervisory lines, enlisting company health care staff, and referring to medical resources outside of the company [42]. Concerning the fourth approach, medical resources are not limited to psychosomatic practitioners or other clinics/hospitals; for example, employee assistance programs (EAPs) have attracted a great deal of attention in Japan since 2000 as promising medical resources outside the workplace. Originally, EAPs were employer-sponsored systems developed to restore or improve the functioning of workers whose personal problems were affecting job performance [43]. Newer, more comprehensive EAPs engage in identification, assessment, monitoring, referral, short-term counseling, and follow-up activities with regard to the emotional, financial, legal, family, and substance-abuse concerns of employees. In this sense, comprehensive EAPs are new in Japan and primarily target the mental health care of employees. In our cohort study of 283 male Japanese employees who accessed EAP services [44], total scores on the 17-item Hamilton Depression Scale after the 2year study period decreased significantly on five items: suicidal thoughts, agitation, psychomotor retardation, guilt, and depressed mood. Specifically, 19 (86\%) of the 22 workers with a positive response to the suicidal thoughts item at baseline (i.e., score $\geq 1$ ) reported no suicidal thoughts after the 2 -year study period (i.e., score $=0$ ). No significant changes were observed in the control group. These data suggest that introducing an EAP may decrease perceived psychosocial stress in a working population.

\section{Conclusions}

Work-related stress is commonly seen in psychosomatic medicine clinics. The job demand-control-support model and the ERI model are recognized as reliable and useful for assessing job stress. Both unemployment and job insecurity are regarded as risk factors associated with increased mortality and morbidity in a variety of physical and psychological disease conditions. A significant body of research reveals that temporary workers have reported chronic work-related stress for years. To manage stress in the workplace, a combination of individual-focused and organization-focused approaches is the most promising [45], and the following four approaches are recommended for comprehensive mind/body health 
care in the workplace: focusing on individuals, utilizing supervisory lines, enlisting company health care staff, and referring to medical resources outside the company.

In the occupational health field, medical professionals have many roles, including regular health examinations of employees, health consultation with symptomatic employees, and regular monitoring of the work environment to protect all workers. In addition, metabolic syndrome health examinations and special examinations for employees with excessive work schedules are current concerns in the Japanese workplace. Because physicians specializing in psychosomatic medicine can assess both physical and psychological illness, they are often asked to perform such assessments in the workplace. Medicine should not be limited to disease treatment in a hospital; it is also important to prevent disease. To practice psychosomatic medicine in the hospital requires a trusting relationship between the patient and doctor, and both must be aware of the power of the mind-body connection. Communication is the key factor for developing this relationship. This is also true for the relationship between the employee and occupational health physician and between the occupational health physician and the physician in charge at the hospital, who see the same patient in different settings. For example, good communication helps employees with psychosomatic distress to recover and return to work. For this reason, it is critical for psychosomatic practitioners and researchers to understand the basic ideas of workrelated stress from the viewpoint of occupational health.

\section{Acknowledgements \\ The author proposed and submitted this manuscript to BioPsychoSocial Medicine after agreement with the Editorial Committee of the Japanese Society of Occupational Health $(\mathrm{JOH})$. The author appreciates the support of all JOH editorial members who attended the March 2010 conference. \\ Author details \\ 'Department of Hygiene and Public Health, Teikyo University School of Medicine, Tokyo, Japan. ${ }^{2}$ Division of Psychosomatic Medicine, Teikyo University Hospital, Tokyo, Japan.}

\section{Authors' contributions}

The author wrote the manuscript and holds final responsibility for the decision to submit the manuscript for publication.

\section{Competing interests}

The author declare that they have no competing interests.

Received: 7 May 2010 Accepted: 26 May 2010 Published: 26 May 2010

\section{References}

1. Japanese Ministry of Health and Welfare: National Survey of Health 2004. Tokyo: Kosei Toukei Kyoukai 2006.

2. The Committee of Education and Training of the Japanese Society of Psychosomatic Medicine: An updated treatment guideline of psychosomatic medicine. Jpn J Psychosom Med 1991, 31:537-576.

3. American Psychiatric Association: Diagnostic and statistical manual of mental disorders, fourth edition, text revision. Washington, D.C.: American Psychiatric Press 2000.
4. American Psychiatric Association: Diagnostic and statistical manual of mental disorders: Washington, D.C.: American Psychiatric Press, third 1987.

5. Nakao M, Nomura S, Yamanaka G, Kumano H, Kuboki T: Assessment of patients by DSM-III-R and DSM-IV in a Japanese psychosomatic clinic. Psychother Psychosom 1998, 67:43-49.

6. Keegel T, Ostry A, Lamontagne AD: Job strain exposures vs. stress-related workers' compensation claims in Victoria, Australia: developing a public health response to job stress. J Public Health Policy 2009, 30:17-39.

7. Kawakami N, Tsutsumi A: Job stress and mental health among workers in Asia and the world. J Occup Health 2010, 52:1-3.

8. National Institute for Occupational Safety and Health: Stress at work. Cincinnati: NIOSH 1999.

9. Kivimäki M, Leino-Arjas P, Luukkonen R, Riihimäki H, Vahtera J, Kirjonen J: Work stress and risk of cardiovascular mortality: prospective cohort study of industrial employees. BMJ 2002, 325-857.

10. Xu W, Zhao Y, Guo L, Guo Y, Gao W: Job stress and coronary heart disease: a case-control study using a Chinese population. J Occup Health 2009, 51:107-113.

11. Nomura K, Nakao M, Takeuchi T, Yano E: Associations of insomnia with job strain, control, and support among male Japanese workers. Sleep Med 2009, 10:626-629.

12. Stoetzer $U$, Ahlberg $G$, Johansson $G$, Bergman $P$, Hallsten $L$, Forsell $Y$, Lundberg I: Problematic interpersonal relationships at work and depression: a Swedish prospective cohort study. J Occup Health 2009, 51:144-151.

13. Noblet A, Lamontagne AD: The role of workplace health promotion in addressing job stress. Health Promot Int 2006, 21:346-353.

14. Cooper CL, Baglioni AJ Jr: A structural model approach toward the development of a theory of the link between stress and mental health. Br J Med Psychol 1988, 61:87-102.

15. LaMontagne AD, Keegel T, Vallance D: Protecting and promoting mental health in the workplace: developing a systems approach to job stress. Health Promot J Austr 2007, 18:221-228.

16. LaMontagne AD, Keegel T, Louie AM, Ostry A, Landsbergis PA: A systematic review of the job-stress intervention evaluation literature, 1990-2005. Int J Occup Environ Health 2007, 13:268-280.

17. Karasek R, Theorell T: Healthy work: stress, productivity and the reconstruction of the working life. New York: Basic Books 1990.

18. Siegrist J: Adverse health effects of high effort-low reward conditions at work. J Occup Health Psychol 1996, 1:27-43.

19. Stahl SM, Haunger RL: Stress: an overview of the literature with emphasis on job-related strain and intervention. Adv Ther 1994, 11:110-119.

20. Karasek R: Job demands, job decision latitude and mental strain: implication for job redesign. Administr Sci Q 1979, 24:285-308.

21. Stansfeld S, Candy B: Psychosocial work environment and mental health: a meta-analytic review. Scand J Work Environ Health 2006, 32:443-462.

22. Johnson JV, Hall EM: Job strain, work place social support, and cardiovascular disease: a cross-sectional study of a random sample of the Swedish working population. Am J Public Health 1988, 78:1336-1342.

23. Eller NH, Netterstrøm B, Gyntelberg F, Kristensen TS, Nielsen F, Steptoe A, Theorell T: Work-related psychosocial factors and the development of ischemic heart disease: a systematic review. Cardiol Rev 2009, 17:83-97.

24. Karasek R, Gorden G, Pietrovsky C, Frese M, Pieper C: Job content instrument: questionnaire and user's guide. Los Angeles: University of South California 1985.

25. Kawakami N, Fujigaki Y: Reliability and validity of the Japanese version of Job Content Questionnaire: replication and extension in computer company employees. Ind Health 1996, 34:295-306.

26. Nomura K, Nakao M, Karita K, Nishikitani M, Yano E: Association between work-related psychological stress and arterial stiffness measured by brachial-ankle pulse wave velocity in young Japanese males in an information-service company. Scand J Work Environ Health 2005, 31:352-359.

27. Schnall PL, Landsbergis PA, Baker D: Job strain and cardiovascular disease. Annu Rev Public Health 1994, 15:381-411.

28. Greenlund KJ, Liu K, Knox S, McCreath H, Dyer AR, Gardin J: Psychosocial work characteristics and cardiovascular disease risk factors in young adults: the CARDIA study. Coronary Artery Risk Disease in Young Adults. Soc Sci Med 1995, 41:717-723. 
29. Siegrist J, Klein D, Voigt KH: Linking sociological with physiological data: the model of effort-reward imbalance at work. Acta Physiol Scand Suppl 1997, 640:112-116.

30. Tsutsumi A, Ishitake T, Peter R, Siegrist J, Matoba T: The Japanese version of the Effort-Reward Imbalance Questionnaire: a study in dental technicians. Work Stress 2001, 15:86-96.

31. Takaki J, Nakao M, Karita K, Nishikitani M, Yano E: Relationships among effort-reward imbalance, overcommitment, and fatigue in Japanese information-technology workers. J Occup Health 2006, 48:62-64.

32. Dooley D, Fielding J, Levi L: Health and unemployment. Annu Rev Public Health 1996, 17:449-465.

33. Artazcoz L, Benach J, Borrell C, Cortès I: Unemployment and mental health: understanding the interactions among gender, family roles, and social class. Am J Public Health 2004, 94:82-88.

34. Kompier M, Ybema JF, Janssen J, Taris T: Employment contracts: crosssectional and longitudinal relations with quality of working life, health and well-being. J Occup Health 2009, 51:193-203.

35. Benach J, Benavides FG, Platt S, Diez-Roux A, Muntaner C: The healthdamaging potential of new types of flexible employment: a challenge for public health researchers. Am J Public Health 2000, 90:1316-1317.

36. Aronsson G: A new employment contract. Scand J Work Environ Health 2001, 27:361-364.

37. Virtanen M, Kivimäki M, Ferrie JE, Elovainio M, Honkonen T, Pentti J, Klaukka T, Vahtera J: Temporary employment and antidepressant medication: a register linkage study. J Psychiatr Res 2008, 42:221-229.

38. Nakao M: Psychosocial stress in diseases related to lifestyles. Jpn J Psychosom Med 2008, 48:195-203.

39. Stybel LJ, Peabody M: The right way to be fired. Harv Bus Rev 2001, 79:86-95.

40. Nakao M, Yano E: A comparative study of behavioral, physical, and mental health status between term-limited and tenure-track employees in a population of Japanese male researchers. Public Health 2006, 120:373-379.

41. Virtanen $M$, Kivimäki $M$, Joensuu $M$, Virtanen $P$, Elovainio $M$, Vahtera J: Temporary employment and health: a review. Int J Epidemiol 2005, 34:610-622.

42. Japanese Ministry of Health, Labour, and Welfare: Guideline for promoting mental health care in enterprise. Tokyo: Japanese Industrial Safety and Health Association 2001

43. Colantonio A: Assessing the effects of employee assistance programs: a review of employee assistance program evaluations. Yale J Biol Med 1989, 62:13-22.

44. Nakao M, Nishikitani M, Shima S, Yano E: A 2-year cohort study on the impact of an Employee Assistance Programme (EAP) on depression and suicidal thoughts in male Japanese workers. Int Arch Occup Environ Health 2007, 81:151-157.

45. Semmer NK: Job stress interventions and the organization of work. Scand J Work Environ Health 2006, 32:515-527.

doi:10.1186/1751-0759-4-4

Cite this article as: Nakao: Work-related stress and psychosomatic medicine. BioPsychoSocial Medicine 2010 4:4.

\section{Submit your next manuscript to BioMed Central and take full advantage of:}

- Convenient online submission

- Thorough peer review

- No space constraints or color figure charges

- Immediate publication on acceptance

- Inclusion in PubMed, CAS, Scopus and Google Scholar

- Research which is freely available for redistribution

Submit your manuscript at www.biomedcentral.com/submit
Biomed Central 